\title{
Revisiting the Assignment of Innocent and Non-Innocent Counter ions in Lanthanide(III) Solution Chemistry
}

\author{
Nicolaj Kofod, Maria Storm Thomsen $\ddagger$, Patrick Nawrocki \& \& Thomas Just Sørensen* \\ Nano-Science Center \& Department of Chemistry, University of Copenhagen, Universitetsparken 5, 2100 Kфbenhavn $\emptyset$,
}

Denmark

tjs@chem.ku.dk

\begin{abstract}
Lanthanides are found in critical applications from display technology to renewable energy. Often these rare earth elements are used as alloys or functional materials, yet the access to them are trough solution processes. In aqueous solution the rare earths are found predominantly as trivalent ions and charge balance dictates that counter ions are present. The fast ligand exchange and lack of directional bonding in lanthanides complexes has led to questions regarding the speciation of $\mathrm{Ln}^{3+}$ solvates in the presence of various counter ions, and to the distinction between innocent $=$ noncoordinating, and non-innocent $=$ coordinating counter ions. There is limited agreement as to which counter ions that belong to each group, which lead to this report. By using $\mathrm{Eu}^{3+}$ luminescence, it was possible to clearly distinguish between coordinating and non-coordinating ions. To interpret the results it was required to bridge the descriptions of ion pairing and coordination. The data-in form of $\mathrm{Eu}^{3+}$ luminescence spectra and luminescence lifetimes from solutions with varying concentrations of acetate, chloride, nitrate, fluoride, sulfate, perchlorate and triflate-were contrasted to those obtained with ethylenediaminetetraaceticacid (EDTA), which allowed for the distinction between three $\mathrm{Ln}^{3+}$-anion interaction types. It was possible to conclude which counter ions are truly innocent (e.g. $\mathrm{ClO}_{4}^{-}$and $\left.\mathrm{OTf}^{-}\right)$, and which clearly coordinate (e.g. $\mathrm{NO}_{3}{ }^{-}$and $\left.\mathrm{AcO}^{-}\right)$. Finally, the considerate amount of data from systems studied under similar conditions allowed the minimum perturbation arising from inner sphere or outer sphere coordination in $\mathrm{Eu}^{3+}$ complexes to be identified.

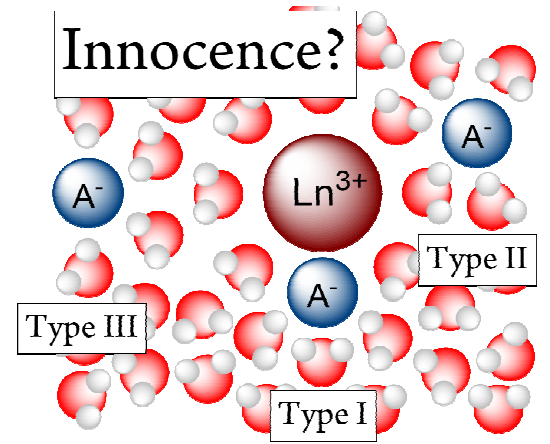

\section{Introduction}

The metal-ligand interactions in trivalent lanthanide complexes are often regarded purely as electrostatic. In spite of this, the trivalent lanthanides form strong solvates in e.g. water, DMSO, and methanol. ${ }^{1-6}$ It is not uncommon that these uncharged solvent ligands outcompete negatively charged anions, forming outer-sphere complexes with an inner coordination sphere composed purely of coordinating solvent. More strongly coordinating ligands can outcompete the solvent and coordinate directly to the metal ion. As no bonding occurs, these types of interactions would typically be described in terms of ion pairs. ${ }^{7}$ In order to understand the solution chemistry of the $\mathrm{Ln}^{3+}$ ions we must consider these ion pairing effects.

Marcus \& Hefter $^{7}$ categorize three different ion pair typessolvent separated, solvent shared, and close contact ion pairs. This description works well for organic molecules, where the solvent acts only as a solvent shell. For metal ions, especially those with fast ligand exchange such as the lanthanides, ${ }^{8}$ this description becomes problematic as the distinctions between the coordination spheres and solvent shells are inconsistent. For example, the water molecules in close contact to a metal ion are typically regarded as ligands and not as a solvent shell. Further, the solvent separated ion pair used by Marcus \& Hefter is identical to two complex ions in close contact. In order to avoid confusion, we have categorized the metal-anion interactions into four Types (see Figure 1). In Type I, there is direct coordination of the anion to the metal ion. In this case, the anion acts as a ligand in the inner coordination sphere. In Type II, the anion resides in the second coordination sphere of the metal ion, with the anion and metal ion sharing the solvent ligand from the inner coordination sphere of the metal ion. In Type III, both metal ion and anion retains their own inner coordination sphere-described as the first solvent shell by Marcus \& Hefter-but with the coordination spheres in close contact. Type IV denotes the 
free ions, with no restrictions on the ion mobility nor any appreciable interaction energy.

With a focus on lanthanide solution chemistry, we can conclude that all of metal-anion interaction types will have different effects on the symmetry of the ligand field experienced by the central metal $\left(\mathrm{Ln}^{3+}\right)$ ion. As the ligand field is directly linked to the electronic structure of the lanthanide ion, we can follow these interactions using optical spectroscopy. Of the lanthanide ions, the most attractive candidate for this is $\mathrm{Eu}^{3+}$ owing to the intense luminescence, easy detectability in the visible range and singly degenerate ground and emitting state. We thus chose to use $\mathrm{Eu}^{3+}$ luminescence as a reporter to investigate and assign metal-anion interaction in solutions containing EDTA, acetate, nitrate, chloride, fluoride, carbonate, triflate, sulfate, bisulfate and perchlorate.

The metal-anion interaction types of $\mathrm{Eu}^{3+}$ and common anions has been widely studied before, (Table 1) but in different systems and using a wide array of techniques. This leaves us with a muddled picture of the interactions types. The historical nomenclature defines coordinating anions (Types I-II) as noninnocent counter ions, and non-coordinating (Types III-IV) as innocent counter ions. Some ions appear as both in the literature, see Table 1 . In this study, we set out to systematically study the coordination of the most common anions, and assign a distinct metal-anion interaction type using specific experimental conditions. It is important to note, that while we measure ionic strength and $\mathrm{pH}$ of all samples, we do not attempt to keep these constant. Therefore, we are not reporting binding constants, but qualify metal-anion interaction Types and investigate when we can with certainty assign an observation to a $\mathrm{Ln}^{3+}$ centred interaction (Type I, Figure 1).

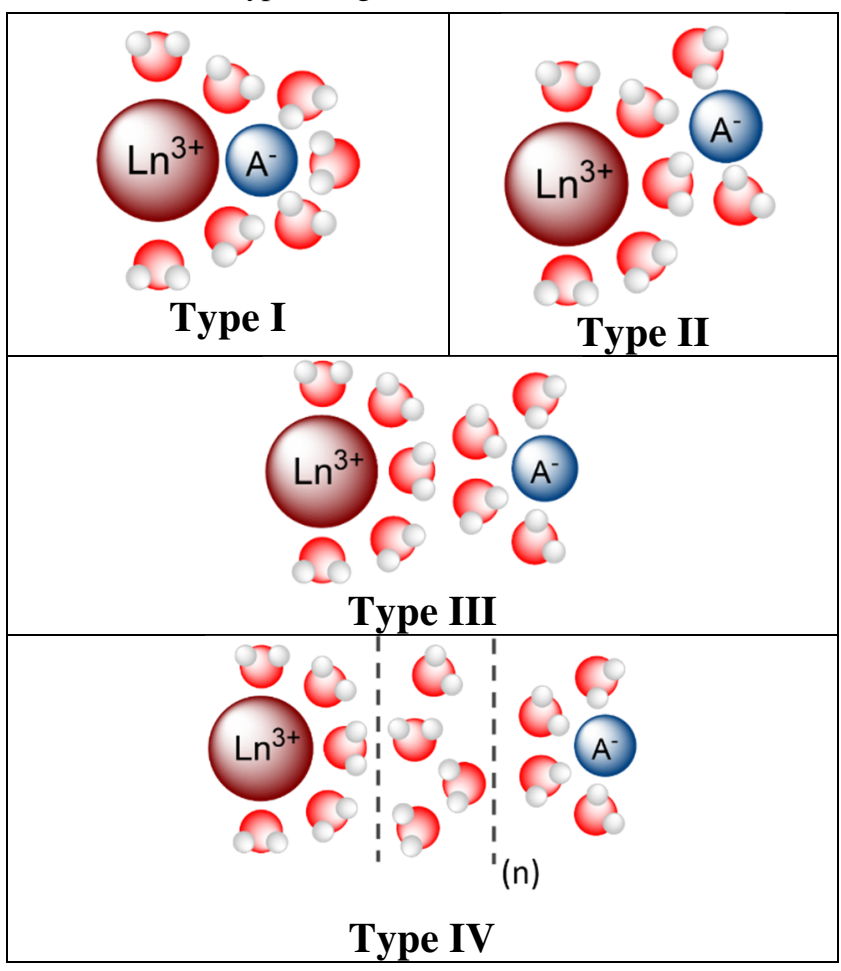

Figure 1. Illustration of the four different types of metal-anion interactions between metal $\left(\mathrm{Ln}^{3+}\right)$ ions and anions $\left(\mathrm{A}^{-}\right)$.

\section{Experimental}

Sample Preparation. All chemicals were used as received. $\mathrm{Eu}\left(\mathrm{CF}_{3} \mathrm{SO}_{3}\right)_{3}(98 \%$, STREM Chemicals), $\mathrm{KCl}$ (MERCK), $\mathrm{NaCl}$ (Th. Geyer), MES (SIGMA Chemical Company), $\mathrm{Na}\left(\mathrm{CF}_{3} \mathrm{SO}_{3}\right.$ ) (Sigma-Aldrich), $\quad \mathrm{NaClO}_{4} \quad$ (Fluka AG), $\mathrm{NaHSO}_{4} \cdot \mathrm{H}_{2} \mathrm{O}$ (MERCK), $\mathrm{Na}_{2} \mathrm{SO}_{4}$ (Chemsolute), $\mathrm{NaNO}_{3}$ (Sigma-Aldrich), $\mathrm{K}\left(\mathrm{CH}_{3} \mathrm{COO}\right)$ (Sigma-Aldrich), $\mathrm{H}_{4}$ EDTA (from our own supply).

$\mathrm{A} \mathrm{Eu}^{3+}$ stock solution containing $\mathrm{KCl}$ was made by adding $2.01 \mathrm{~g}(0.0033 \mathrm{~mol}) \mathrm{Eu}\left(\mathrm{CF}_{3} \mathrm{SO}_{3}\right)_{3}, 1.42 \mathrm{~g}(0.0066 \mathrm{~mol}) \mathrm{MES}$ buffer (solid), and $24.85 \mathrm{~g} \mathrm{KCl}(0.333 \mathrm{~mol})$ to a $250 \mathrm{ml}$ volumetric flask and dissolved by adding demineralized water to the $250 \mathrm{ml}$ mark. The buffer was adjusted with $1 \mathrm{M} \mathrm{NaOH}$ to $\mathrm{pH}=$ 5.5. The stock solution was used for samples with the ligands: chloride, fluoride, nitrate, sulfate and acetate. $\mathrm{A} \mathrm{Eu}^{3+}$ stock solution containing $\mathrm{NaCl}$ was made by adding $1.99 \mathrm{~g}(0.0033 \mathrm{~mol})$ $\mathrm{Eu}\left(\mathrm{CF}_{3} \mathrm{SO}_{3}\right)_{3}, 1.42 \mathrm{~g}(0.0066 \mathrm{~mol}) \mathrm{MES}$ buffer (solid), and $19.48 \mathrm{~g} \mathrm{NaCl}(0.333 \mathrm{~mol})$ to a $250 \mathrm{ml}$ volumetric flask and dissolved by adding demineralized water to the $250 \mathrm{ml}$ mark. The buffer was adjusted with $1 \mathrm{M} \mathrm{NaOH}$ to $\mathrm{pH}=5.5$. The $\mathrm{NaCl}$ containing buffer was used for samples with the ligands: perchlorate and EDTA, because the use of the $\mathrm{KCl}$ containing buffer resulted in precipitation. The concentrations in the stock solutions were $0.0132 \mathrm{M} \mathrm{Eu}\left(\mathrm{CF}_{3} \mathrm{SO}_{3}\right)_{3}, 0.0132 \mathrm{M} \mathrm{NaCl} / \mathrm{KCl}$ and 0.0264 M MES.

Ligand solutions were made by dissolving a sodium or potassium salt of the ligand in demineralized water in a volumetric flask:

Triflate: $3.44 \mathrm{~g} \mathrm{Na}\left(\mathrm{CF}_{3} \mathrm{SO}_{3}\right)$ was dissolved in a $5 \mathrm{ml}$ volumetric flask to give a concentration of $4 \mathrm{M}$.

Chloride: $1.16 \mathrm{~g} \mathrm{NaCl}$ was dissolved in a $5 \mathrm{ml}$ volumetric flask to give a concentration of $4 \mathrm{M}$.

Perchlorate: $12.25 \mathrm{~g} \mathrm{NaClO}_{4}$ was dissolved in a $25 \mathrm{ml}$ volumetric flask to give a concentration of $4 \mathrm{M}$.

Nitrate: $16.99 \mathrm{~g} \mathrm{NaNO}_{3}$ was dissolved in a $25 \mathrm{ml}$ volumetric flask to give a concentration of $8 \mathrm{M}$.

Bisulfate: $6.91 \mathrm{~g} \mathrm{NaHSO}_{4} \cdot \mathrm{H}_{2} \mathrm{O}$ was dissolved in a $25 \mathrm{ml}$ volumetric flask to give a concentration of $2 \mathrm{M}$.

Sulfate: $7.10 \mathrm{~g} \mathrm{Na}_{2} \mathrm{SO}_{4}$ was dissolved in a $25 \mathrm{ml}$ volumetric flask to give a concentration of $2 \mathrm{M}$.

Acetate: $19.3 \mathrm{~g} \mathrm{~K}\left(\mathrm{CH}_{3} \mathrm{COO}\right)$ was dissolved in a $50 \mathrm{ml}$ volumetric flask to give a concentration of $4 \mathrm{M}$. Additionally, 5.89 $\mathrm{g} \mathrm{K}\left(\mathrm{CH}_{3} \mathrm{COO}\right)$ was dissolved in a $10 \mathrm{ml}$ volumetric flask to give a concentration of $6 \mathrm{M}$.

EDTA: $0.875 \mathrm{~g} \mathrm{H}_{4}$ EDTA was added to a $25 \mathrm{ml}$ volumetric flask and $10 \mathrm{ml}$ of water. The compound was dissolved by the addition of approx. $1 \mathrm{ml}$ of $2 \mathrm{M} \mathrm{NaOH}$. The flask was then filled with water up to the $25 \mathrm{ml}$ mark give a concentration of $0.12 \mathrm{M}$ with $\mathrm{pH}=8.7$.

The solutions were diluted to a range of concentrations. The samples where then prepared by mixing in a new vial, $3 \mathrm{ml}$ of the $\mathrm{Eu}^{3+}$ stock solution and $1 \mathrm{ml}$ of a diluted ligand solution. The final concentration of $\mathrm{Eu}^{3+}$ in the samples was $0.01 \mathrm{M}$, the concentration of $\mathrm{NaCl} / \mathrm{KCl}$ was $0.01 \mathrm{M}$, the final concentration of MES was $0.02 \mathrm{M}$, the ligand concentration varies as indicated in all data. Sample compositions as well as $\mathrm{pH}$ and conductivity of the sample can be seen in Table S1. 
Optical Spectroscopy. All optical measurements were carried out in $10 \mathrm{~mm}$ quartz cuvettes from Starna Scientific.

Absorption measurements were performed on a Lambda 1050 double-beam spectrophotometer from Perkin Elmer using a stock solution of $0.020 \mathrm{M}$ MES and $1.0 \mathrm{M} \mathrm{KCl}$ or $\mathrm{NaCl}$ as reference. Slits were kept at $1.5 \mathrm{~nm}$. Absorption was measured on an absolute scale from air $(100 \%$ transmission; Abs $=0)$ to a blocked beam $(0 \%$ transmission; Abs $=\infty)$.

Steady State and Time-Resolved Emission spectra were recorded on a PTI QuantaMaster 8075 instrument from Horiba Scientific using a Xenon arc lamp for Steady State excitation and a Xenon flash lamp for Time-Resolved excitation. Temperatures were maintained at $20{ }^{\circ} \mathrm{C}$ using a Koolance EXT-440 liquid cooling system from Horiba Scientific. Emission/excitation slits were kept at $8 \mathrm{~nm} / 1.5 \mathrm{~nm}$ for emission spectrum determination, $1.5 \mathrm{~nm} / 8 \mathrm{~nm}$ for excitation spectrum determination and $8 \mathrm{~nm} / 5 \mathrm{~nm}$ when recording emission decay profiles. In emission measurements, excitation was done at $394 \mathrm{~nm}$. In excitation measurements, emission was measured at $594 \mathrm{~nm}$. In emission decay measurements, excitation was done at $394 \mathrm{~nm}$ and emission was recorded at $594 \mathrm{~nm}$. Wavelength dependence of the detector sensibility was corrected using a factory supplied correction file. Fluctuations in lamp intensity was corrected using a reference detector. No signals from other lanthanides were detected. All available spectra, luminescence decay traces and fit parameters are available in the SI.

pH and Conductivity. Conductivity was measured on a Mettler Toledo SevenCompact Conductivity meter S230, and the $\mathrm{pH}$ was measured on a Mettler Toledo SevenCompact InLab Expert Pro ISM pH meter.

\section{Results \& Discussion}

Starting point. Table 1 shows a curated overview of previous studies of the coordination between $\mathrm{Eu}^{3+}$ and small inorganic anions as well as the different techniques used to study the metal-anion interactions, and an assignment of the interaction types determined in these works. For contrast, we have included the strong chelating ligand EDTA with the smaller anions. EDTA is one of the most studied chelators of $f$-block elements and is undoubtedly Type I. ${ }^{9-13}$ This is reflected in Table 1 , where all studies and all techniques agrees that the ligand coordinates in the inner coordination sphere in direct contact with the $\mathrm{Ln}^{3+}$ ion. EDTA is thus a clear example of a direct ion pair, or Type I interaction. On the other end of the spectrum, $\mathrm{ClO}_{4}{ }^{-}$ shows little to no coordination to $\mathrm{Ln}^{3+}$ ions in any of the studies. ${ }^{12,14-20}$ Even at high concentrations of $\mathrm{ClO}_{4}{ }^{-}$, there is no optical response. At extremely high concentrations $\mathrm{ClO}_{4}^{-}$has shown interactions with $\mathrm{Ln}^{3+}$ ions but we attribute this to spatial constraints (vide infra). ${ }^{21}$ For this reason $\mathrm{ClO}_{4}{ }^{-}$is often used as an "innocent" ion in $\mathrm{Ln}^{3+}$ studies - either as the $\mathrm{Ln}^{3+}$ source or as an electrolyte. More recently, OTf- has been used in a similar manner. While OTf- has received far less attention, it has been shown to exhibit no coordination to $\mathrm{Eu}^{3+}$. This is also true in less coordinating solvents such as $\mathrm{MeOH} .{ }^{3}$ Both $\mathrm{ClO}_{4}{ }^{-}$and $\mathrm{OTf}^{-}$ exhibit clear Type III metal-anion interaction.

In between EDTA and $\mathrm{ClO}_{4}{ }^{-} / \mathrm{OTf}^{-}$the picture is less clear. $\mathrm{AcO}^{-}$is consistently determined as coordinating (Type I), but with a much lower binding constant than EDTA. For most small ligands, accurate determinations of binding constants are made difficult by the possibility of several coordination events. Similarly, there has been little debate regarding the coordination of $\mathrm{F}^{-}$and $\mathrm{CO}_{3}{ }^{2-} \cdot{ }^{20,22-26}$ Both ligands are clearly Type I, binding to the aqua ions in aqueous media and binding to free coordination sites of $\mathrm{Ln}^{3+}$ complexes such as DOTA and DO3A. ${ }^{27-28,29 . .}$ There are few studies regarding the binding constants of carbonate and fluoride to lanthanide(III) aqua-ions due to the low solubility of the salts in aqueous solution. As part of this study, we confirmed this observation, as addition of carbonate, fluoride, phosphate, acac and hfac all immediately resulted in precipitation when added to our system.

$\mathrm{NO}_{3}{ }^{-}$is one of the more controversial anions regarding coordination. Nitrate has been extensively studied due to its high relevance in nuclear fuel reprocessing and lanthanide separations. Earlier studies often characterized the $\mathrm{Ln}^{3+}$-nitrate interaction as outer sphere (Type II). ${ }^{20,22,30-35}$ These results were often based on solvent extraction. Later studies based on optical spectroscopy consistently showed Type I interaction. ${ }^{3,12,14-19,36-}$ ${ }^{41}$ Similarly, $\mathrm{SO}_{4}{ }^{2-}$ and $\mathrm{HSO}_{4}{ }^{-}$has given rise to some debate regarding the coordination type. Studies using optical spectroscopy mostly find Type I metal-anion interaction, while other studies, mainly based on solvent extraction, find Type $\mathrm{II}^{-} \mathrm{Cl}^{-}$, in contrast to $\mathrm{F}^{-}$, consistently shows Type II or even Type III metal-anion interaction. ${ }^{12,15-22,31-33,41-44}$ It has often been used as an innocent anion background. There are however, some evidence of $\mathrm{LnCl}^{2+}$ forming in solution and a Type III interaction is not well established.

Table 1. Assignment of metal-anion interactions types between $\mathrm{Ln}^{3+}$ ions and selected anions from the literature.

\begin{tabular}{|c|c|c|c|}
\hline Ligand & Type & Technique & Ref \\
\hline \multirow{5}{*}{ EDTA } & I & Potentiometric/Polygraphic & 45 \\
\hline & I & Review & 10 \\
\hline & I & Radiotracer & 46 \\
\hline & I & Optical & 47 \\
\hline & I & Calorimetric & 13 \\
\hline \multirow{3}{*}{$\mathrm{AcO}^{-}$} & I & Solvent Extraction & 48 \\
\hline & I & Review & 10 \\
\hline & I & Optical & $49-50$ \\
\hline \multirow{8}{*}{$\mathrm{NO}_{3}^{-}$} & I & Optical, Lifetimes & $14-16$ \\
\hline & I & Optical & $\begin{array}{l}17-18,36-40, \\
47\end{array}$ \\
\hline & I & Ultrasound Absorption & 51 \\
\hline & I & X-ray (EXAFS) & 41 \\
\hline & I & Optical, X-ray & 3 \\
\hline & $\mathrm{I}+\mathrm{II}$ & Optical, NMR, density & 52 \\
\hline & $\mathrm{I} / \mathrm{II}$ & Solvent Extraction & $31-33,35,53$ \\
\hline & II & Review & 20,22 \\
\hline \multirow{5}{*}{$\begin{array}{l}\mathrm{HSO}_{4}^{-} \\
/ \mathrm{SO}_{4}{ }^{2-}\end{array}$} & I & Optical Lifetime & 16 \\
\hline & I & Optical & $54-55$ \\
\hline & I & Ultrasound & 56 \\
\hline & $\mathrm{I} / \mathrm{II}$ & Solvent extraction & $\begin{array}{l}33,42,48,57- \\
58\end{array}$ \\
\hline & II & Review & 20 \\
\hline
\end{tabular}




\begin{tabular}{|c|c|c|c|}
\hline \multirow{5}{*}{$\mathrm{F}^{-}$} & I & Review & 20,22 \\
\hline & $\mathrm{I} / \mathrm{II}$ & Multiple & 24 \\
\hline & $\mathrm{I} / \mathrm{II}$ & Potentiometric & 25 \\
\hline & $\mathrm{I} / \mathrm{II}$ & Solvent Extraction (not Eu) & 26 \\
\hline & II & Optical & 39 \\
\hline $\mathrm{CO}_{3}{ }^{2-}$ & $\mathrm{I} / \mathrm{II}$ & Solvent extraction & 23 \\
\hline \multirow{11}{*}{$\mathrm{Cl}^{-}$} & I & Optical & 18 \\
\hline & $\mathrm{I} / \mathrm{II}$ & Optical Lifetime & 15 \\
\hline & II & Review & 20 \\
\hline & II & Solvent Extraction & $31-33,42-43$ \\
\hline & II & Optical & 47 \\
\hline & II & Potentiometric & 59 \\
\hline & II/III & Ultrasound & 51 \\
\hline & III & Optical Lifetime & 16 \\
\hline & III & Review & $21-22$ \\
\hline & III & X-ray, EXAFS & 41 \\
\hline & III & Optical, Lifetimes & 17 \\
\hline \multirow{4}{*}{$\mathrm{ClO}_{4}^{-}$} & III & Optical & 14,47 \\
\hline & III & Optical Lifetime & $15-18$ \\
\hline & III & Ultrasound absorption & 19 \\
\hline & III & Review & 20 \\
\hline OTf $^{-}$ & III & Optical, X-ray & 3 \\
\hline
\end{tabular}

Highest Achievable Metal-Anion Distance. In this study, as well as many industrial processes, the concentrations of anions often exceeds $1 \mathrm{M}$. At these concentrations, the spatial distribution of the ions in the sample must be considered. Assuming equilibrium with a uniform density of the sample, then a $0.01 \mathrm{M}$ solution of metal ions will have a maximum distance between the centers of neighboring metal ions of $68 \AA$. The value is found by a trivial calculation using equations $1,2 \& 3$ :

$V_{\mathrm{M}}=\frac{V}{n_{\mathrm{M}} \cdot N_{\mathrm{A}}}$

$r_{\mathrm{M}}=\left(\frac{V_{\mathrm{M}}}{\frac{4}{3} \pi}\right)^{1 / 3}$

$d_{\mathrm{M}-\mathrm{M}}=2 \cdot\left(r_{\mathrm{M}}-I R_{\mathrm{M}}\right)$

where $V$ is the volume of the sample, $n_{\mathrm{M}}$ is number of $\mathrm{M}$ ions in the sample in moles, $N_{\mathrm{A}}$ is Avogadro's number, $V_{\mathrm{M}}$ is the volume of the solvent sphere each metal ion resides in, $r_{M}$ is the radius of this sphere, $I R_{\mathrm{M}}$ is the ionic radii of metal and $d_{\mathrm{M}-\mathrm{M}}$ is the distance between the edge of the metal ions in solution.

If we assume that there are no interactions between metal ions and the anions, we can calculate the highest possible distance between the metal ions and the anions at any concentration. With anion concentrations lower than the metal ion concentration, here $0.01 \mathrm{M}$, the system can be seen as anions in a metal ion lattice. In this domain the highest possible distance between metal ions and anions lie directly between two metal ions, and is thus equal to $r_{M} / 2=34 \AA$. When the concentration of anions exceed that of the metal ions, the system can be seen as metal ions in an anion lattice. In this domain the highest possible distance between metal ions and anion becomes half the anion-anion distance.

For the systems studied here, we can map the maximum distances at between $\mathrm{Eu}^{3+}$ and anion at any concentration. This is done by exchanging the $0.01 \mathrm{M}$ molar $\mathrm{Eu}^{3+}$ concentration in eq 1 and 2 with the concentration the anion concentration of the anions when both are $0.01 \mathrm{M}$ or higher. The result is shown in Figure 2. In the $\mathrm{Eu}^{3+}$ domain $\left(\mathrm{C}_{\mathrm{Eu}}>\mathrm{C}_{\text {anion }}\right)$ the highest possible distance is $34 \AA$. In the anion domain $\left(\mathrm{C}_{\mathrm{Eu}}<\mathrm{C}_{\mathrm{anion}}\right)$ the highest possible distance decreases as the concentration of anion increases. The approximate size of the inner and outer coordination sphere, as well as the ionic radius of $\mathrm{Eu}^{3+}$ are indicated in Figure 2. This treatment illustrates that the perturbations of the electronic structure, which are dominated by the inner coordination sphere, at concentrations lower than $\sim 2 \mathrm{M}$ must be due to metal-ligand interactions.

Electrostatic Charge Separation. Assuming ideal point charges, the potential energy required for charge separation can be calculated using equation 4

$V=\frac{Q_{1} \cdot Q_{2}}{4 \cdot \pi \cdot \varepsilon_{0} \cdot \varepsilon_{r} \cdot r}$

Where $\mathrm{V}$ is the potential energy of charge separation, $Q_{1}$ and $Q_{2}$ are the charges of the two point charges, $\varepsilon_{0}$ is the vacuum permittivity, $\varepsilon_{\mathrm{r}}$ is the relative permittivity of the solvent and $r$ is the distance between the two point charges. With a $\mathrm{A}^{-}$anion and a $\mathrm{M}^{3+}$ cation in water equation 4 gives the function shown in Figure 3. As can be seen from Figure 3, any electrostatic interactions between $\mathrm{A}^{-}$and $\mathrm{M}^{3+}$ ions separated by more than $5 \AA$ (such as Type III and Type IV, vide supra) will be smaller than the thermal energy of $4 \mathrm{k}_{\mathrm{B}} \mathrm{T}$ at $300 \mathrm{~K}$. This treatment assumes no shielding from other ligands.

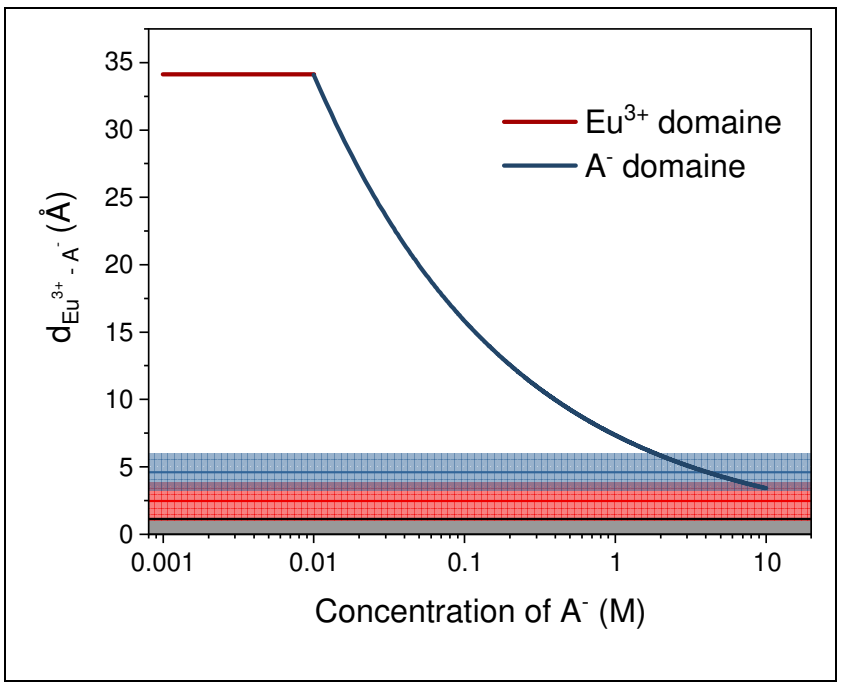

Figure 2. Calculated maximal distance between anion $\left(\mathrm{A}^{-}\right)$and $\mathrm{Eu}^{3+}$ in a $0.01 \mathrm{M} \mathrm{Eu}^{3+}$ solution as a function of anion concentration. The colors indicate the $\mathrm{Eu}^{3+}$ ionic radius (grey), the inner coordination sphere (red) and the outer coordination sphere (blue). A coulombic radius of $1.4 \AA$ was used for water and an ionic radius of $1.120 \AA$ was used for $\mathrm{Eu}^{3+}$. The distances are measured from the center of the atoms (see main text). 


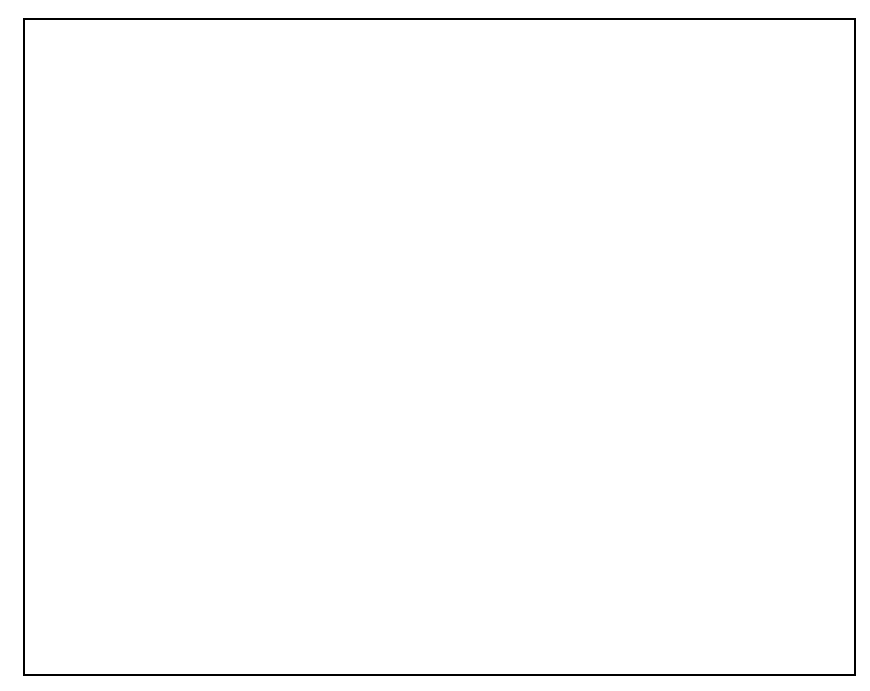

Figure 3. Illustration of the simple interaction energy between a $\mathrm{M}^{3+}$ and a $\mathrm{A}^{-}$point charge in water (black) as a function of distance. The horizontal line (yellow) shows the $4 \mathrm{k}_{\mathrm{B}} \mathrm{T}$ energy at $300 \mathrm{~K}$. The vertical lines show the ionic radii of $\mathrm{Eu}^{3+}$ (grey), ${ }^{60}$ the first coordination sphere (red) and the second coordination sphere (blue).

System Description. It has been shown that the speciation of $\mathrm{Ln}^{3+}$ complexes in solution can be affected by $\mathrm{pH}$ and ionic strength. ${ }^{35,61-62}$ To minimize any such effects we perform all titrations in a buffer (0.02 M MES) and with a high background electrolyte ( $1 \mathrm{M} \mathrm{NaCl}$ or $\mathrm{KCl}$ ), see the experimental section for details. This ensures that while the ionic strength (conductivity) and $\mathrm{pH}$ are not constant, the changes between samples are relatively small. In order to verify the innocence of the ion and $\mathrm{Eu}^{3+}$ salts used, we performed a series of screening titrations. Figure S42-S52 shows emission, excitation and time-resolved emission decay profiles of $\mathrm{Eu}(\mathrm{OTf})_{3}$ with and without added OTf $\mathrm{Eu}(\mathrm{OTf})_{3}$ with and without added $\mathrm{Cl}^{-}, \mathrm{EuCl}_{3}$ with and without added OTf- $^{-}$, and $\mathrm{Eu}(\mathrm{OTf})_{3}$ with and without added MES. No changes in the spectra are seen in any of the experiments, clearly showing the innocence of the solvent system.

Classifying metal-anion interactions. Optical spectroscopy directly reveal the electronic structure of $\mathrm{Eu}^{3+}$ ions. ${ }^{3,63}$ Thus, we are able to distinguish the different metal-anion interactions types, with the effects summarized in Figure 4.

For Type I there is a significant perturbation of the ligand field symmetry and donor set. This will give rise to a different spectral shape of the luminescence. This is easily identified in the ${ }^{5} \mathrm{D}_{0} \rightarrow{ }^{7} \mathrm{~F}_{4}$ and ${ }^{5} \mathrm{D}_{0} \rightarrow{ }^{7} \mathrm{~F}_{0}$ bands of the $\mathrm{Eu}^{3+}$ emission spectrum. For the sake of consistency, we will use the 700/690 nm and 700/696 $\mathrm{nm}$ ratios as a measure of the band shape of ${ }^{5} \mathrm{D}_{0} \rightarrow$ ${ }^{7} \mathrm{~F}_{4}$ transitions. When forming Type I complexes, the removal of $\mathrm{O}-\mathrm{H}$ oscillators in the inner coordination sphere will remove non-radiative energy transfer pathways of the ${ }^{5} \mathrm{D}_{0}$ electronic state. This will result in a longer excited state lifetime and a higher emission intensity of the $\mathrm{Eu}^{3+}$ luminescence. The ${ }^{5} \mathrm{D}_{0} \rightarrow$ ${ }^{7} \mathrm{~F}_{2}$ (defined as $606-637 \mathrm{~nm}$ in this study) band is especially sensitive to changes in the coordination environment and thus we will use the integrated intensity of this band as the measure for changes in intensity.

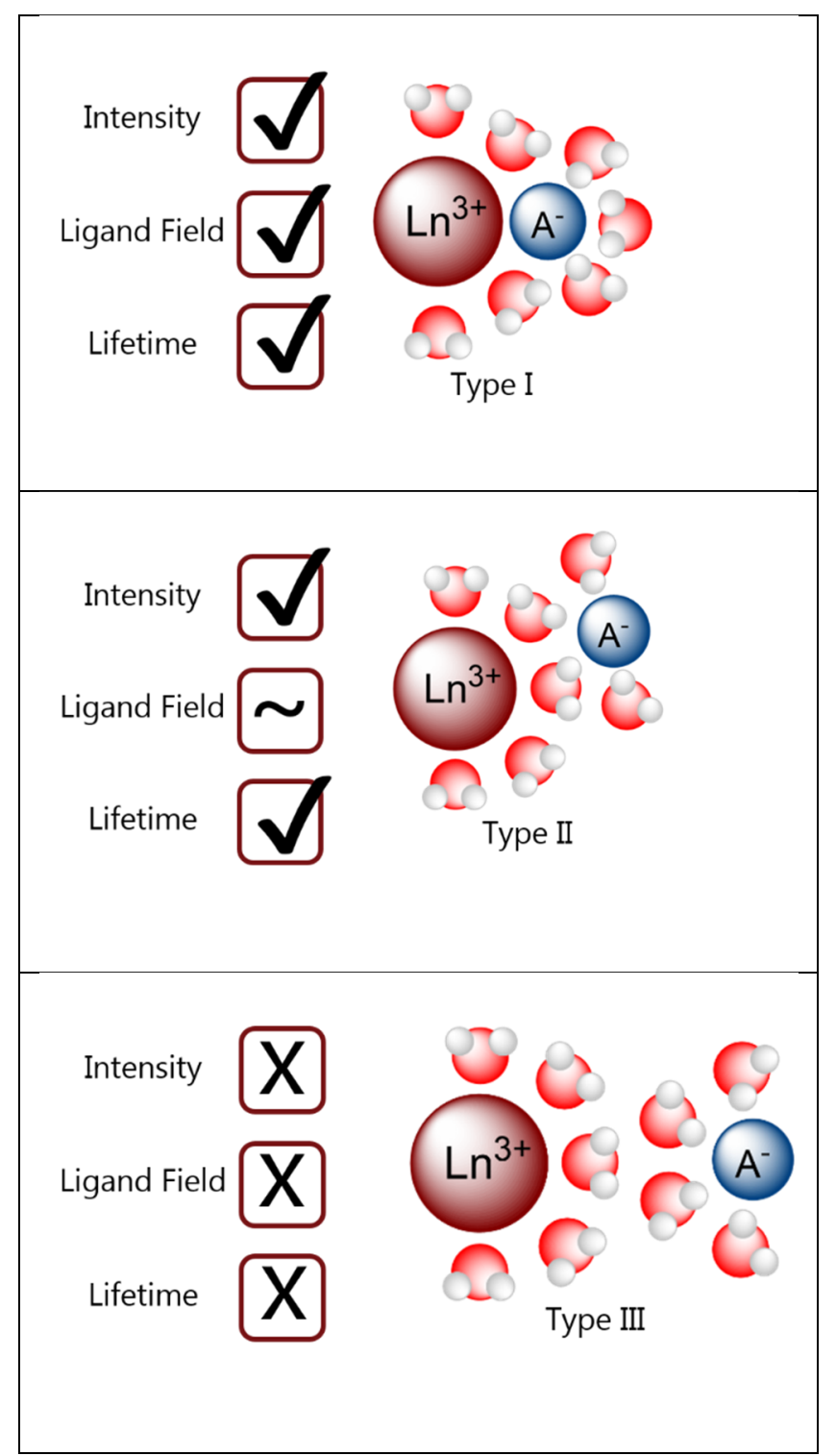

Figure 4. Overview of the expected experimental changes in $\mathrm{Eu}^{3+}$ luminescence for the different metal-anion interaction types. Type I: Changes in Emission Intensity, Ligand Field splitting and Excited State Lifetime (top). Type II: Changes in Intensity, minor changes in Ligand Field Splitting and changes in excited state lifetime (center). Type III: No changes in emission intensity, ligand field splitting nor lifetime (bottom).

Type II is harder to recognize. We argue that the anions in the second coordination sphere will interact with the inner sphere solvent molecules through e.g. hydrogen bonding. This will affect the bond distance to the inner sphere ligands and thus increase the excited state lifetime and emission intensity of the $\mathrm{Eu}^{3+}$ ion. Since the donor set still consists exclusively of solvent ligands and their position is not significantly affected, the band shape caused by the ligand field will remain largely unperturbed. While the band shape will remain largely intact as the anion is introduced, a change in the hypersensitve ${ }^{5} \mathrm{D}_{0} \rightarrow{ }^{7} \mathrm{~F}_{2}$ intensity is expected.

For Type III coordination, the donor set consisting of purely solvent ligands will be unperturbed by the introduced anion. 
Therefore, emission intensity, band shape, and excited state lifetime will not be affected by the changes in the anion concentration. The same is true for Type IV. It is not possible to distinguish Type III and Type IV using optical spectroscopy. In theory, these two types can be distinguished using conductivity. In this study, we are interested in the coordination of the anions and therefore we do not attempt to differentiate between Type III and Type IV.

Type I metal-anion interactions. In this study, we use EDTA as the reference point of Type I metal-anion interactions. There is no debate over the coordination of EDTA to $\mathrm{Ln}^{3+}$ ions in solution (see Table 1). The chelating nature of the ligand results in a strong entropic driving force for coordination. As expected, addition of the ligand gives rise to a large change in emission intensity, band shape and excited state lifetime (Figures 5, 9a, and Table 2). The excited state lifetime increases from $121 \mu$ s to $311 \mu \mathrm{s}$, while the intensity of the ${ }^{5} \mathrm{D}_{0} \rightarrow{ }^{7} \mathrm{~F}_{2}$ band increases tenfold from 3.06 to 29.42 . The changes in band shape are also identifiable in the $700 / 690 \mathrm{~nm}$ ratio, which changes from 4.6 to 1.9. As such, EDTA is a clear Type I ligand. We note that neither intensity nor excited state lifetime converges at 1 equivalent, which would be expected for 1:1 coordination (see Figure S3). We hypothesize that this is due to either a 2:1 ligand to metal coordination complex with two EDTA ligands forming a sandwich complex, or due to interactions of a second EDTA molecule with the solvent shell.

$\mathrm{AcO}^{-}$falls in the same category as EDTA, see Figures 5, 9b, and Table 2. We see clear changes in emission intensity (3.33 to 49.14 for the ${ }^{5} \mathrm{D}_{0} \rightarrow{ }^{7} \mathrm{~F}_{2}$ band), band shape (4.4 to 1.3 and 1.6 to 0.9 for the $700 / 690 \mathrm{~nm}$ and $700 / 696 \mathrm{~nm}$ ratios respectively), and excited state lifetime ( $111 \mu$ s to $272 \mu \mathrm{s})$. These changes are seen at much higher concentrations than for EDTA. This is the result of a significantly lower binding constant for $\mathrm{Eu}: \mathrm{AcO}^{-}$than for
$\mathrm{Eu}$ : EDTA complexes. Additionally, $\mathrm{AcO}^{-}$offers the possibility of multiple coordination events. We tentatively assign two binding events in the data presented here.

$\mathrm{NO}_{3}{ }^{-}$is less obvious in the metal-anion interaction type (Figure 6a). The lifetime increases from $106 \mu$ s to $120 \mu$ s at $100+$ eq of $\mathrm{NO}_{3}{ }^{-}$. The ${ }^{5} \mathrm{D}_{0} \rightarrow{ }^{7} \mathrm{~F}_{2}$ band shows clear changes in intensity as the $\mathrm{NO}_{3}{ }^{-}$concentration is increased, going from 2.91 to 6.89 . In the ${ }^{5} \mathrm{D}_{0} \rightarrow{ }^{7} \mathrm{~F}_{4}$ band we see a shift in the band shape with the $700 / 690 \mathrm{~nm}$ ratio going from 4.2 to 1.9 , and the $700 / 696 \mathrm{~nm}$ ratio going from 1.5 to 0.7 . The change in ligand field is also visible in the ${ }^{5} \mathrm{D}_{0} \rightarrow{ }^{7} \mathrm{~F}_{2}$ band, where the one broad band shifts into two distinct peaks. This indicates a Type I metal-anion interaction. However, the changes are much more subtle for $\mathrm{NO}_{3}$ than for $\mathrm{AcO}^{-}$and EDTA. Yet, the changes in band shape and lifetime clearly indicates Type I coordination. It is possible that $\mathrm{NO}_{3}{ }^{-}$exhibits both Type I and Type II coordination, and as with $\mathrm{AcO}^{-}$the possibility for multiple coordination events exists.

Type II metal-anion interactions. $\mathrm{SO}_{4}^{2-}$ and $\mathrm{HSO}_{4}$ differentiate only in $\mathrm{pH}$ of the solution (see Figure $6 \mathrm{~b}-\mathrm{c}$ ). In this system, the concentrations achievable with $\mathrm{SO}_{4}{ }^{2-}$ and $\mathrm{HSO}_{4}{ }^{-}$is highly limited by the formation of a 10-coordinate $\mathrm{Eu}^{3+}$ complex in $\mathrm{K}_{5} \mathrm{Na}\left(\mathrm{Eu}_{2}\left(\mathrm{SO}_{4}\right)_{6}\right.$ ] crystals. ${ }^{64}$ In the concentration range we can observe, we see changes in excited state lifetime going from 106 to $130 \mu$ s for $\mathrm{HSO}_{4}^{-}$. This is comparable to that observed for $\mathrm{NO}_{3}{ }^{-}$. In contrast to $\mathrm{NO}_{3}{ }^{-}$, the band shape is largely unaffected by the addition of sulfate/bisulfate (6.2 to 5.6 and 1.7 to 2.0 for the $700 / 690 \mathrm{~nm}$ and $700 / 696 \mathrm{~nm}$ ratios respectively). The ${ }^{5} \mathrm{D}_{0} \rightarrow{ }^{7} \mathrm{~F}_{2}$ band changes somewhat in intensity, but little in shape. The largest change is seen in the ${ }^{5} \mathrm{D}_{0} \rightarrow{ }^{7} \mathrm{~F}_{0}$ band which grows in as the $\mathrm{SO}_{4}{ }^{2-} / \mathrm{HSO}_{4}{ }^{-}$is added. The lack of changes in band shape suggests that $\mathrm{SO}_{4}{ }^{2-}$ and $\mathrm{HSO}_{4}{ }^{-}$have Type II interactions.

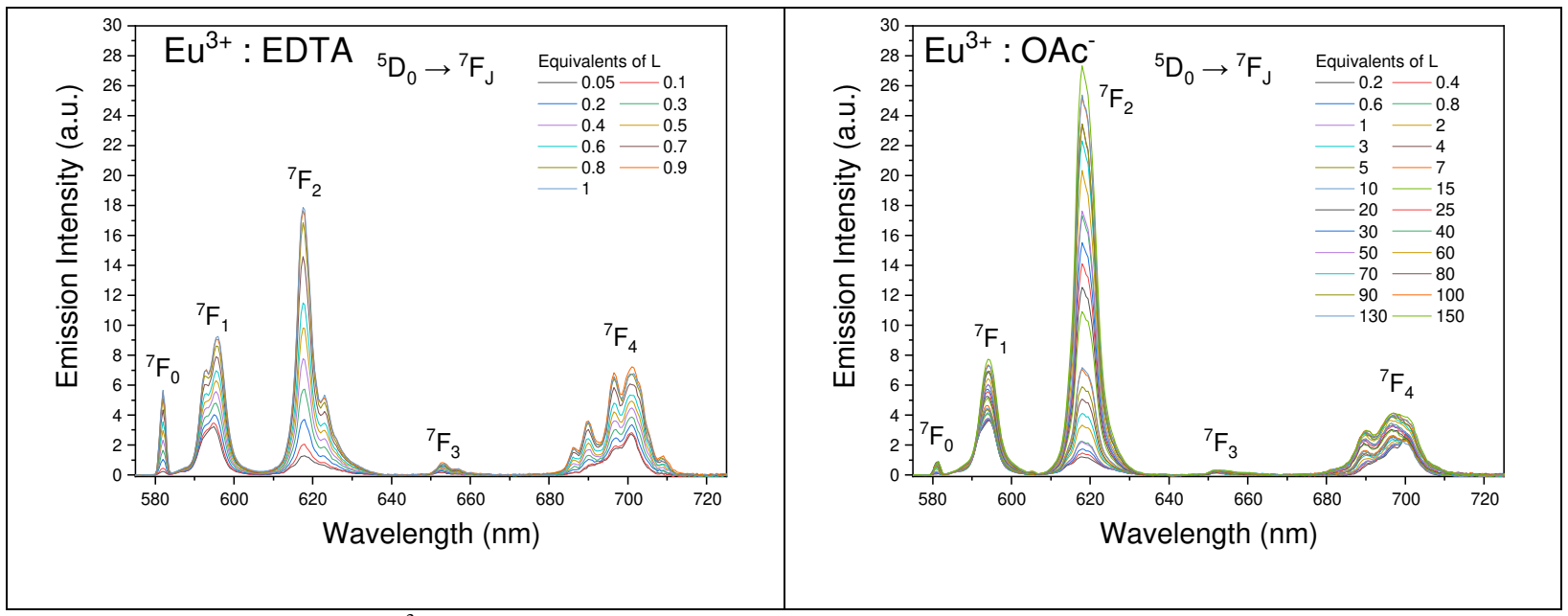

Figure 5. Emission spectra of $\mathrm{Eu}^{3+}$ in NaCl-MES buffer (EDTA) or KCl-MES buffer $\left(\mathrm{AcO}^{-}\right)$with various equivalents of EDTA (right) and $\mathrm{AcO}^{-}$(left) added. Both anions show clear Type I metal-anion interactions (see main text) 


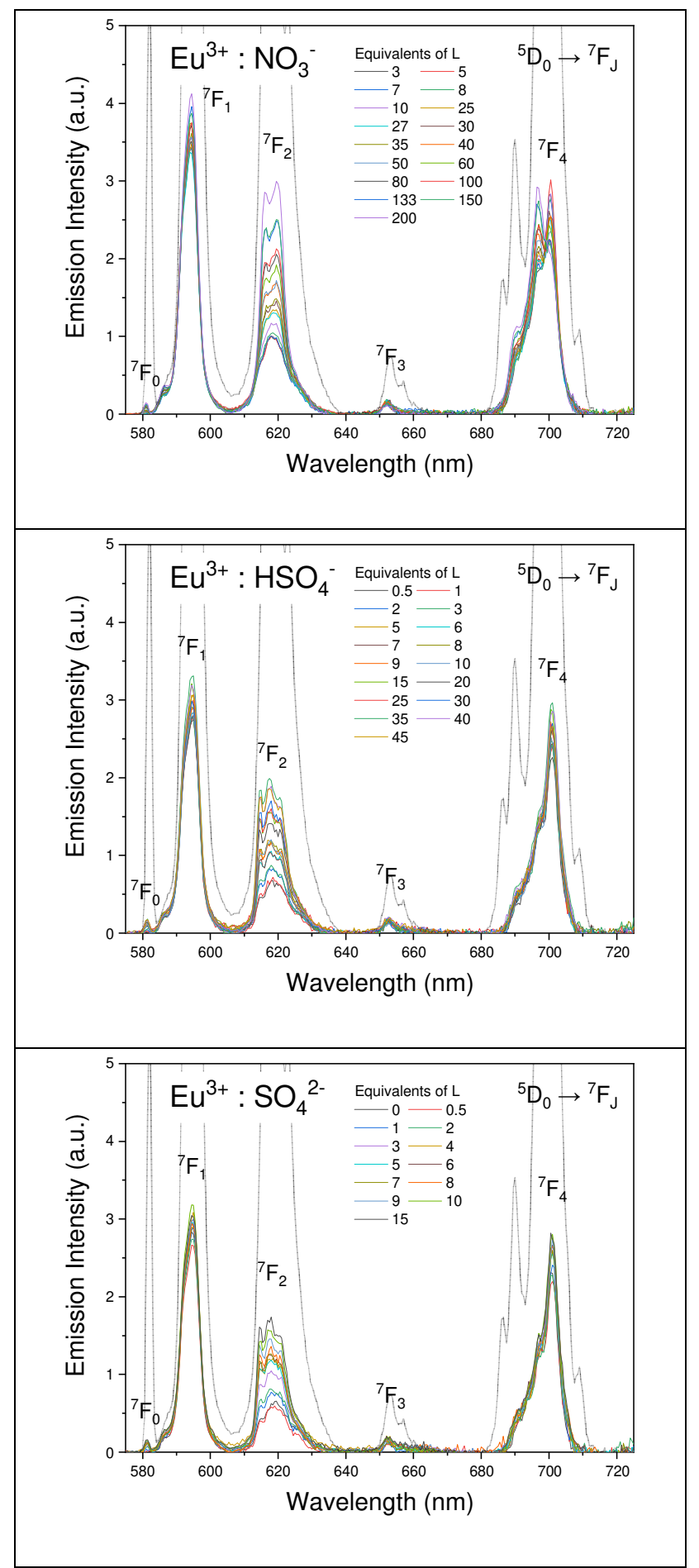

Figure 6. Emission spectra of $\mathrm{Eu}^{3+}$ in NaCl-MES buffer with various equivalents of $\mathrm{NO}_{3}^{-}$(top) $\mathrm{HSO}_{4}^{-}$(middle) and $\mathrm{SO}_{4}{ }^{2-}$ (bottom). The transparent grey trace is from $\mathrm{Eu}^{3+}$ with 1 equivalent of EDTA (see Figure 5). $\mathrm{NO}_{3}{ }^{-}$exhibits Type I coordination while $\mathrm{HSO}_{4}{ }^{-}$and $\mathrm{SO}_{4}{ }^{2-}$ are both Type II metal-anion interactions (see main text)

Type III (Type IV) metal-anion interactions. There is little debate regarding the coordination of $\mathrm{ClO}_{4}^{-}$, vide supra. In accordance with literature, we observe no changes in excited state lifetime, emission intensity or band shape. From this, we can conclude that $\mathrm{ClO}_{4}^{-}$is a clear Type III/IV anion. We observe similar results for $\mathrm{OTf}^{-}$and $\mathrm{Cl}^{-}$with all changes for the 3 ions being well within experimental uncertainties.

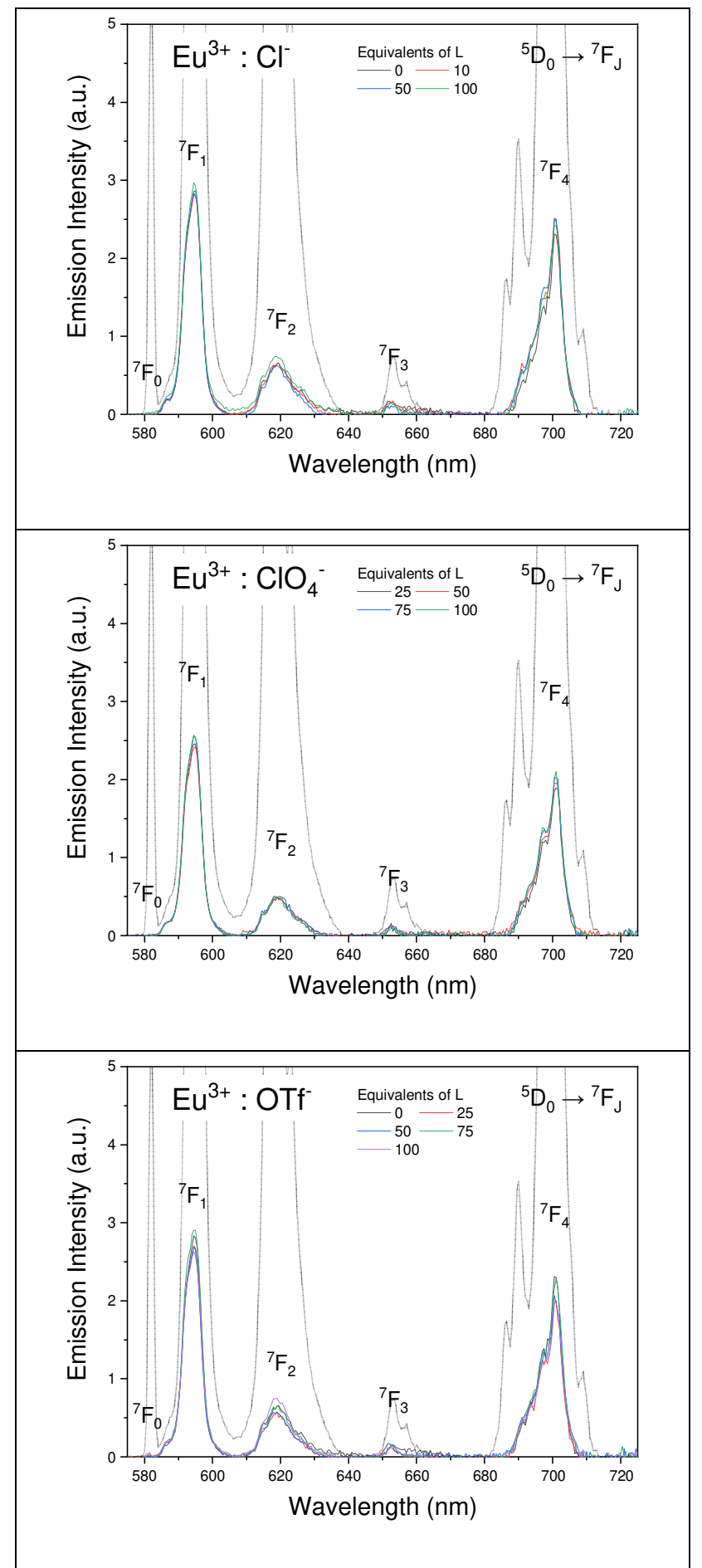

Figure 7. Emission spectra of $\mathrm{Eu}^{3+}$ in $\mathrm{NaCl}-\mathrm{MES}$ buffer $\left(\mathrm{ClO}_{4}^{-}\right)$or $\mathrm{KCl}-\mathrm{MES}$ buffer $\left(\mathrm{Cl}^{-}, \mathrm{OTf}^{-}\right)$with various equivalents of $\mathrm{Cl}^{-}$(top) $\mathrm{ClO}_{4}^{-}$(middle) and $\mathrm{OTf}^{-}$(bottom). The transparent grey trace is from $\mathrm{Eu}^{3+}$ with 1 equivalent of EDTA (see Figure 5). All three ions exhibit clear Type III metal-anion interactions . 
Table 2. Overview of the changes in excited state lifetime, emission intensity and band shape of the ligands studied. The first point clearly different from the aqua ion is highlighted in bold.

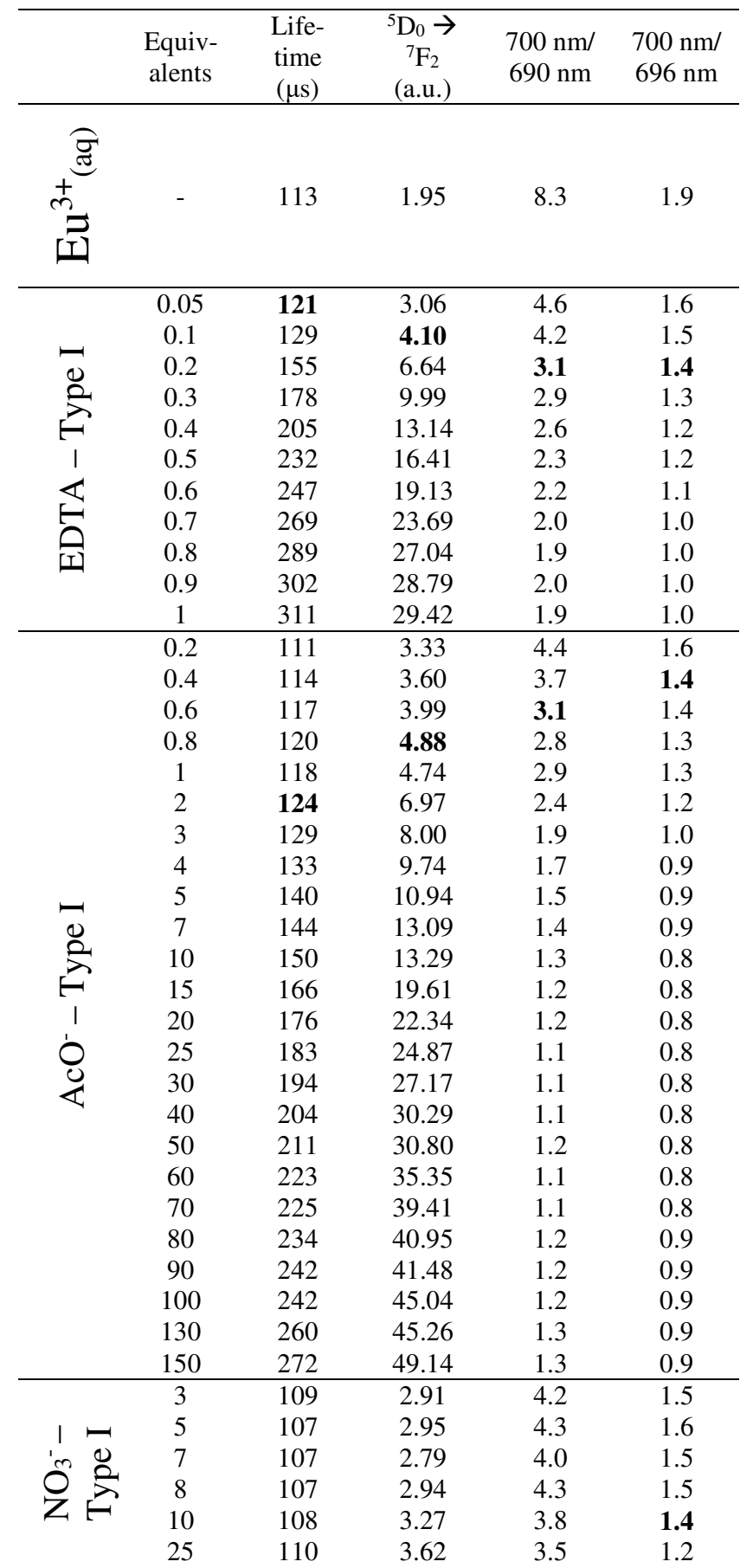

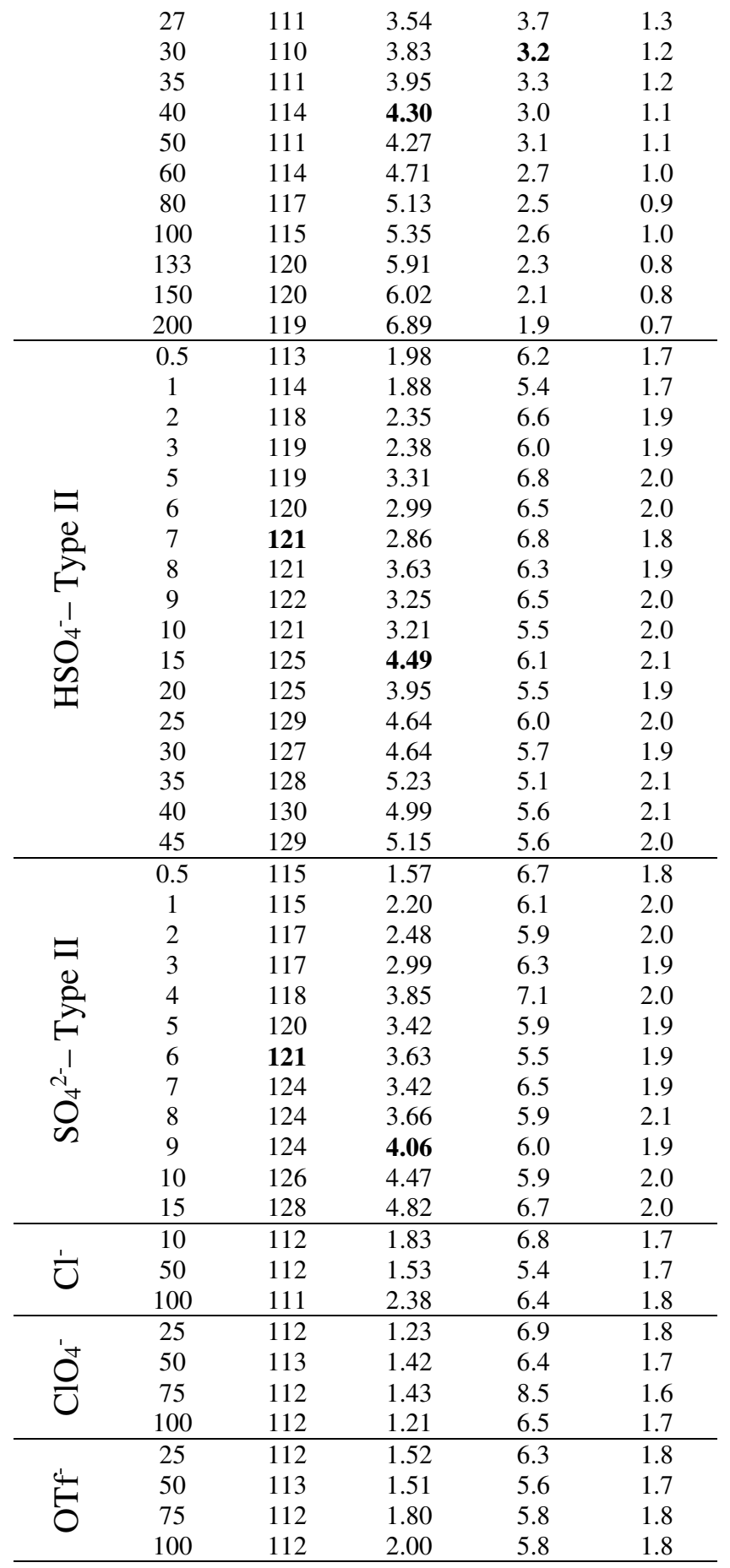




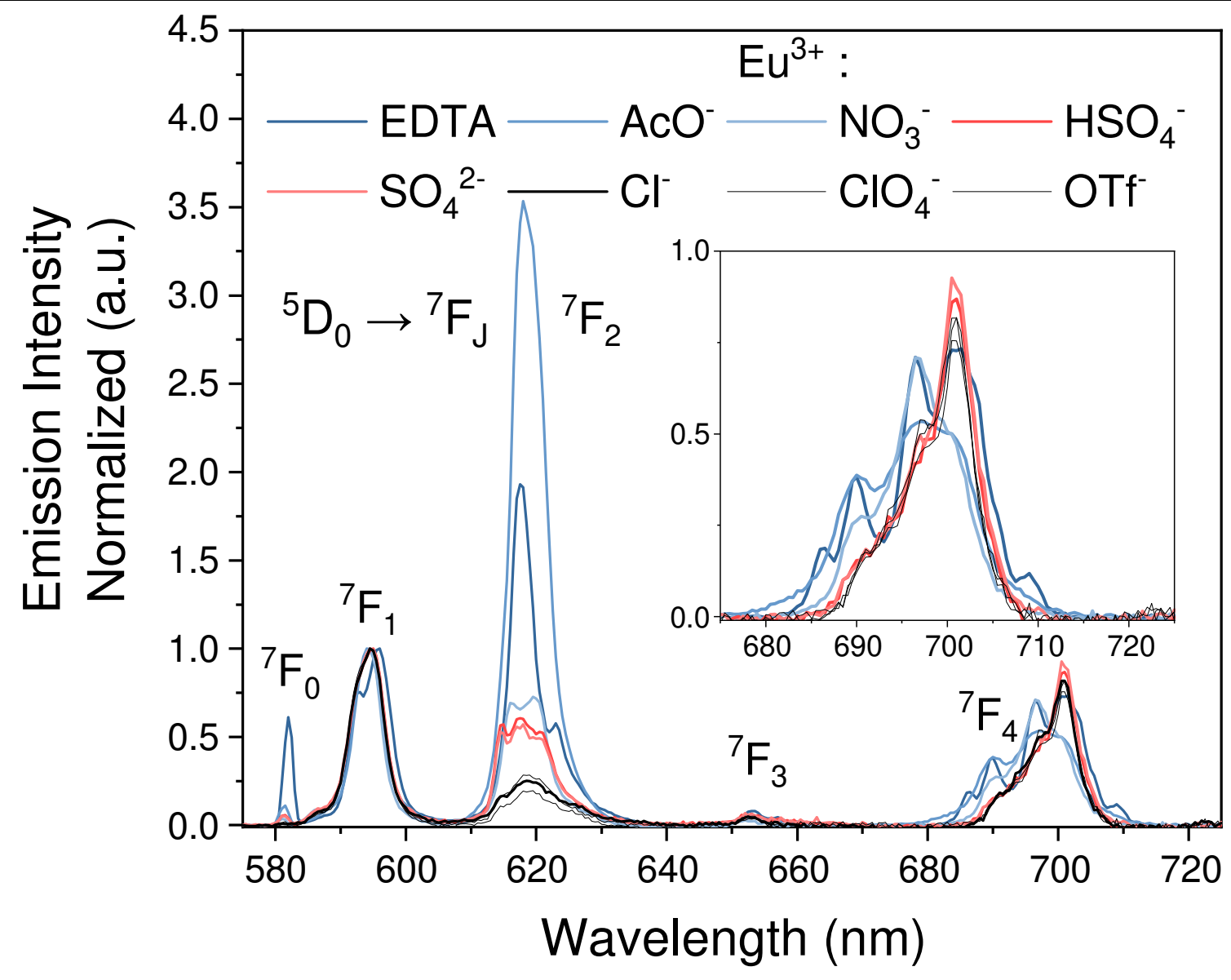

Figure 8. Emission spectra of $\mathrm{Eu}^{3+}$ in NaCl-MES buffer (EDTA, $\left.\mathrm{ClO}_{4}^{-}\right)$or $\mathrm{KCl}-\mathrm{MES}$ buffer $\left(\mathrm{AcO}^{-}, \mathrm{NO}_{3}^{-}, \mathrm{HSO}_{4}^{-}, \mathrm{SO}_{4}^{-}, \mathrm{Cl}^{-} \mathrm{OTf}^{-}\right)$with $\mathrm{EDTA}^{-}$ (1 eq.), $\mathrm{AcO}^{-}$(150 eq.), $\mathrm{NO}_{3}^{-}$(200 eq.), $\mathrm{HSO}_{4}^{-}$(45 eq.), $\mathrm{SO}_{4}^{2-}$ (15 eq.), $\mathrm{Cl}^{-}$(100 eq.) $\mathrm{ClO}_{4}^{-}$(100 eq.) and $\mathrm{OTf}^{-}$(100 eq.) normalized by the ${ }^{5} \mathrm{D}_{0} \rightarrow{ }^{7} \mathrm{~F}_{1}$ band. The traces are color coded by coordination type with Type I in blue, Type II in red and Type III in black. The inset shows a zoom of the ${ }^{5} \mathrm{D}_{0} \rightarrow{ }^{7} \mathrm{~F}_{4}$ band.

Contrasting \& Comparing Coordination Types. Figure 8 shows the emission spectra of the end-point of all 8 titration series normalized by the ${ }^{5} \mathrm{D}_{0} \rightarrow{ }^{7} \mathrm{~F}_{1}$ band. Note that the anion concentrations are orders of magnitude different. As can be seen in the inset of the ${ }^{5} \mathrm{D}_{0} \rightarrow{ }^{7} \mathrm{~F}_{4}$ band the Type I anions (blue) show large differences in the spectral shape of this band, indicating a break of the ligand field symmetry. The Type II (red) and Type III (black) show little to no difference in the ${ }^{5} \mathrm{D}_{0} \rightarrow{ }^{7} \mathrm{~F}_{4}$ band shape. The Type II and Type III differentiate in the ${ }^{5} \mathrm{D}_{0} \rightarrow{ }^{7} \mathrm{~F}_{2}$ band. The Type III ions show no change in the band intensity. In contrast the Type II ions exhibit a significant increase in this peak, even comparable to some of the Type I ions. As mentioned above, we attribute this to perturbations of the solvent coordination sphere by the anions in the second coordination sphere through e.g. hydrogen bonding.
Excited State Lifetimes. Figure 9 shows the excited state lifetimes of $\mathrm{Eu}^{3+}$ as a function of anion concentration. Cursory inspection of Figure 9 reveals that the Type III ions: $\mathrm{Cl}^{-}, \mathrm{ClO}_{4}{ }^{-}$ and $\mathrm{OTf}^{-}$, shows no change in the luminescence lifetime of $\mathrm{Eu}^{3+}$ with increasing anion concentrations. As expected, the obvious Type I anions: EDTA and $\mathrm{AcO}^{-}$, show large effect on the excited state lifetime. $\mathrm{NO}_{3}{ }^{-}$, which we classify as Type I based on the emission spectra (Figure 6a), shows very little change in the excited state lifetime, only increasing to $120 \mu$ s at 200 eq. (Table 2), compared to the $113 \mu$ s of the $\mathrm{Eu}^{3+}$ aqua ion. This is significantly less than the other Type I ions, as well as the Type II ions of $\mathrm{HSO}_{4}{ }^{-}$and $\mathrm{SO}_{4}{ }^{2-}$. This can be explained by considering the differences in the hydrogen bonding of the two ions as the excited state lifetime is highly dependent on O-H oscillators. ${ }^{65}$ 


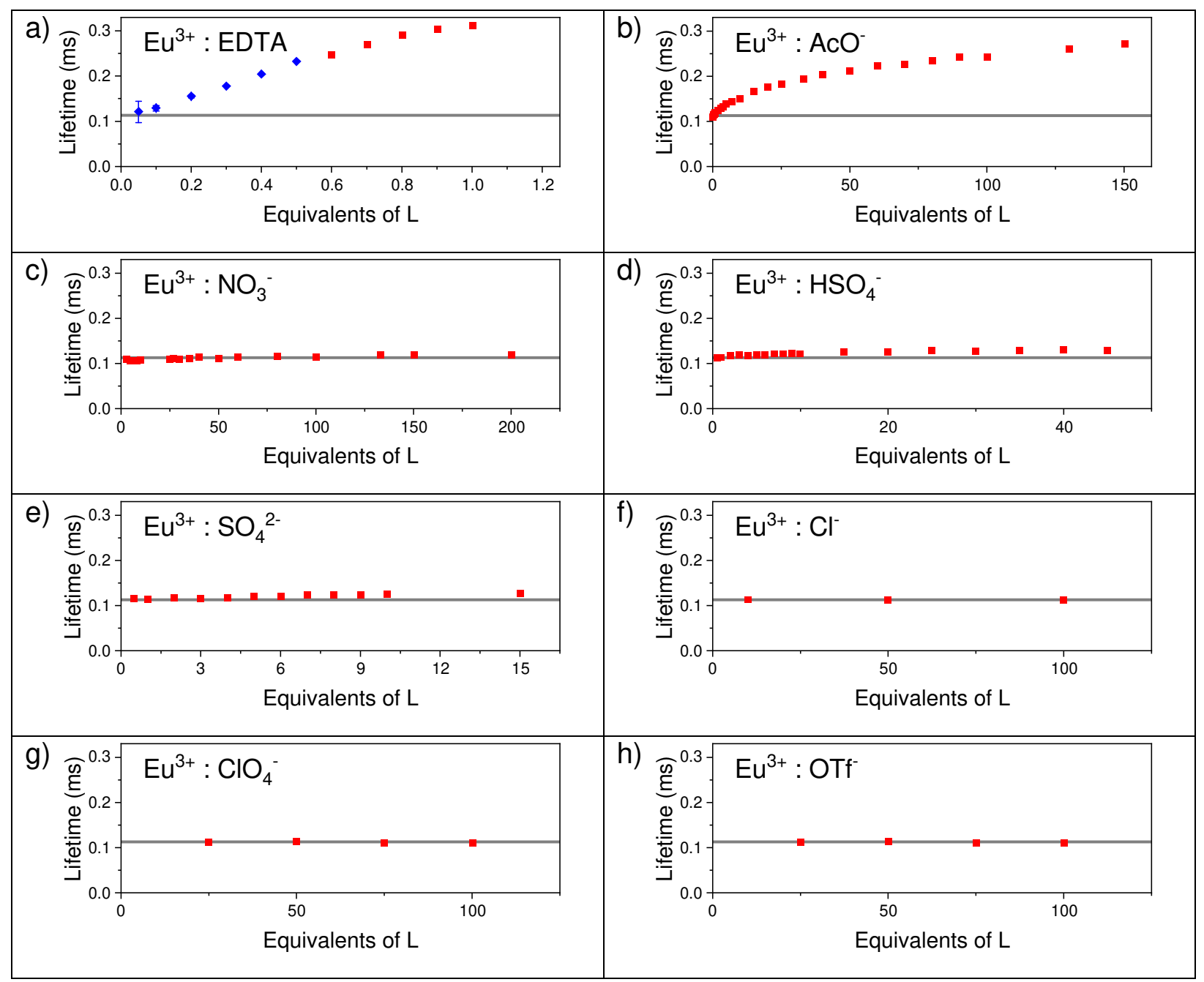

Figure 9. Excited state lifetime of $\mathrm{Eu}^{3+}$ in $\mathrm{NaCl}-\mathrm{MES}$ buffer (EDTA, $\mathrm{ClO}_{4}^{-}$) or KCl-MES buffer $\left(\mathrm{AcO}^{-}, \mathrm{NO}_{3}^{-}, \mathrm{HSO}_{4}^{-}, \mathrm{SO}_{4}^{-}, \mathrm{Cl}^{-} \mathrm{OTf}^{-}\right)$with EDTA (a), $\mathrm{AcO}^{-}(\mathrm{b}), \mathrm{NO}_{3}^{-}(\mathrm{c}), \mathrm{HSO}_{4}^{-}(\mathrm{d}), \mathrm{SO}_{4}{ }^{2-}(\mathrm{e}), \mathrm{Cl}^{-}(\mathrm{f}), \mathrm{ClO}_{4}^{-}(\mathrm{g})$ and $\mathrm{OTf}^{-}(\mathrm{h})$ as a function of equivalents of ligand. The red points are determined from mono-exponential fits of the decay traces. The blue points are the average of the two lifetimes obtained from a bi-exponential fits of the decay trace. The grey line indicates the excited state lifetime of $\mathrm{Eu}^{3+}$ aqua ion. Error bars for all data points except the first $\mathrm{Eu}^{3+}$-EDTA points are smaller than the symbol. 


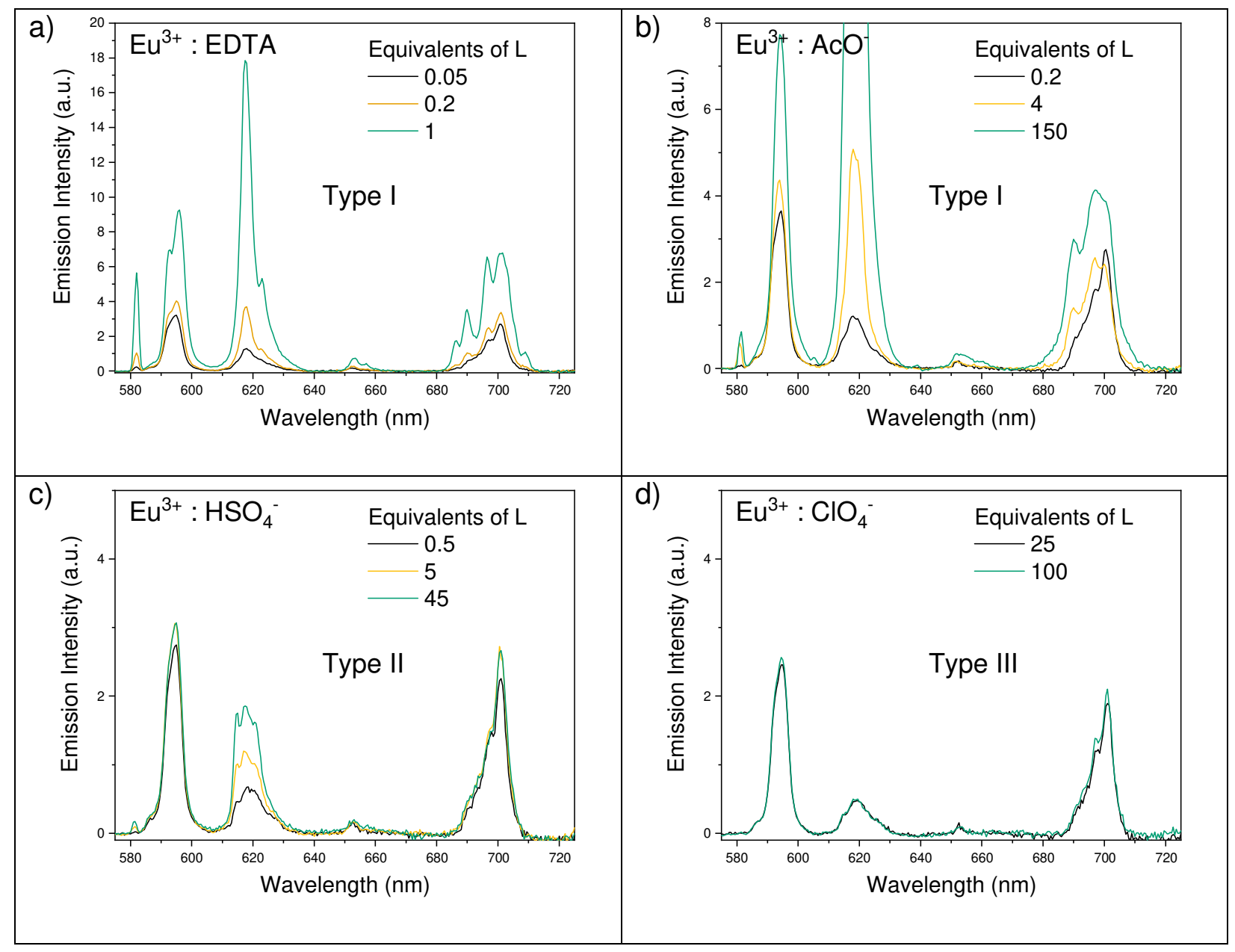

Figure 10. Emission spectra of $\mathrm{Eu}^{3+}$ in $\mathrm{NaCl}-\mathrm{MES}$ buffer (EDTA, $\mathrm{ClO}_{4}^{-}$) or $\mathrm{KCl}_{-} \mathrm{MES}$ buffer $\left(\mathrm{AcO}^{-}, \mathrm{HSO}_{4}^{-}\right)$with $\mathrm{EDTA}^{\text {(a) }} \mathrm{AcO}^{-}(\mathrm{b}) \mathrm{HSO}_{4}^{-}$ (c) and $\mathrm{ClO}_{4}^{-}$(d). The traces shown indicate the starting points of the titration series (black), the limit of distinguishing interactions (yellow) and the end-points in the titration series (green).

Weakest observable interaction. It is interesting to consider the threshold of observable changes by means of optical spectroscopy. Figure 10 shows the emission spectra of $\mathrm{Eu}^{3+}$ with select equivalents of EDTA (10a), $\mathrm{AcO}^{-}(10 \mathrm{~b}), \mathrm{HSO}_{4}^{-}(10 \mathrm{c})$ and $\mathrm{ClO}_{4}^{-}(10 \mathrm{~d})$. From the $\mathrm{Eu}^{3+}$-EDTA spectra we can see that at 0.2 eq. we have significant changes in intensity in all bands as well as small changes in the band shape in the ${ }^{5} \mathrm{D}_{0} \rightarrow{ }^{7} \mathrm{~F}_{4}$ band. The $\mathrm{Eu}^{3+}-\mathrm{ClO}_{4}^{-}$system show no changes even at 100 eq. In the $\mathrm{Eu}^{3+}-$ $\mathrm{AcO}^{-}$spectra we are able to clearly observe changes from 4 eq. The spectral changes does not converge even at 150 eq., which shows the high sensitivity of the technique. For Type II ions such as $\mathrm{HSO}_{4}^{-}$the changes are more subtle and only the ${ }^{5} \mathrm{D}_{0} \rightarrow$ ${ }^{7} \mathrm{~F}_{0}$ and ${ }^{5} \mathrm{D}_{0} \rightarrow{ }^{7} \mathrm{~F}_{2}$ bands show significant intensity changes. The changes in the ${ }^{5} \mathrm{D}_{0} \rightarrow{ }^{7} \mathrm{~F}_{2}$ band are observable from 5 eq. The other bands are largely unaffected even after 45 eq. The spectra in Figure 10 can serve as a guide to when the different type of metal-anion interactions are observed. Note that only Type I interaction corresponds to a metal centered interaction.

\section{Conclusions}

In this study we set out to systematically investigate metalanion interactions types of a series of common anions. Using optical spectroscopy we are able to distinguish between Type I, Type II and Type III metal-anion interactions (see Figure 1).
We find that Type I will induce changes in emission intensity, band shape and excited state lifetimes. Type II will induce slight changes in emission intensity and excited state lifetime, but no effect in the overall band shape of the spectra. Type III will not affect emission intensity, band shape nor the excited state lifetime.

Using the well-studied EDTA as the reference point for clear Type I metal-anion interactions we are able to categorize $\mathrm{AcO}^{-}$ and $\mathrm{NO}_{3}{ }^{-}$as Type I non-innocent and coordinating anions. $\mathrm{AcO}^{-}$ shows clear changes in emission intensity, band shape and excited state lifetime, even at low concentrations. $\mathrm{NO}_{3}{ }^{-}$induced more subtle changes, but we are still able to confidently categorize at least one Type I coordination event. We hypothesize that a second coordination event of either Type I or Type II may also be present for $\mathrm{NO}_{3}{ }^{-}$.

$\mathrm{HSO}_{4}{ }^{-}$and $\mathrm{SO}_{4}{ }^{2-}$ shows changes in emission intensity and excited state lifetime but shows insignificant changes in the band shape, except for the hypersensitive ${ }^{5} \mathrm{D}_{0} \rightarrow{ }^{7} \mathrm{~F}_{2}$ band. Thus, we are able to categorize $\mathrm{HSO}_{4}{ }^{-}$and $\mathrm{SO}_{4}{ }^{2-}$ as Type II anions.

$\mathrm{ClO}_{4}^{-}, \mathrm{Cl}^{-}$and $\mathrm{OTf}^{-}$induce no changes in neither emission intensity, band shape nor excited state lifetime. From this, we can clearly categorize these as Type III innocent and noncoordinating anions. 
Finally, we are able to show examples data for when a metal centred (Type I) can be identified. We hope the differentiation provided in these data will aid the differentiation between binding events and media effects in lanthanide based supramolecular chemistry.

Based on the data provided here, we conclude that only $\mathrm{Cl}^{-}, \mathrm{ClO}_{4}^{-}$and $\mathrm{OTf}^{-}$should be considered as innocent counter ions in solution experiments with lanthanide ions.

\section{ASSOCIATED CONTENT}

Supporting Information. Sample composition; all optical spectra: absorption, emission, time-resolved emission decays; and physicochemical parameters (PDF). This material is available free of charge via the Internet at http://pubs.acs.org.

\section{AUTHOR INFORMATION}

\section{Corresponding Author}

Thomas Just Sørensen - Nano-Science Center and Department of Chemistry, University of Copenhagen, 2100, København Ø, Denmark; tjs@ chem.ku.dk, Orcid: 0000-0003-14915116

\section{Author Contributions}

The manuscript was written through contributions of all authors. $\$$ These authors contributed equally

\section{ACKNOWLEDGMENT}

The authors thank Carlsbergfondet, Villum Fonden (grant\# 14922), the University of Copenhagen, the Danish Chemical Society, and Fulbright Denmark for support.

\section{REFERENCES}

1. Cotton, S.; Harrowfield, J., Solvento complexes of the lanthanide ions. The Rare Earth Elements 2012, 55-63.

2. Kofod, N.; Arppe-Tabbara, R.; Sørensen, T. J., Electronic Energy Levels of Dysprosium(III) ions in Solution. Assigning the Emitting State and the Intraconfigurational $4 \mathrm{f}-4 \mathrm{f}$ Transitions in the Vis-NIR Region and Photophysical Characterization of Dy(III) in Water, Methanol, and Dimethyl Sulfoxide. The Journal of Physical Chemistry A 2019, 123 (13), 2734-2744.

3. Kofod, N.; Nawrocki, P.; Juelsholt, M.; Christiansen, T. L.; Jensen, K. M. Ø.; Sørensen, T. J., Solution Structure, Electronic Energy Levels, and Photophysical Properties of $\left[\mathrm{Eu}(\mathrm{MeOH})_{\mathrm{n}-2 \mathrm{~m}}(\mathrm{NO} 3)_{\mathrm{m}}\right]^{3-\mathrm{m}+}$ Complexes. Inorganic Chemistry 2020.

4. Persson, I.; D'Angelo, P.; De Panfilis, S.; Sandström, M.; Eriksson, L., Hydration of Lanthanoid(III) Ions in Aqueous Solution and Crystalline Hydrates Studied by EXAFS Spectroscopy and Crystallography: The Myth of the "Gadolinium Break". Chemistry - A European Journal 2008, 14 (10), 3056-3066.

5. Kofod, N.; Nawrocki, P.; Platas-Iglesias, C.; Sørensen, T. J., Electronic Structure of Ytterbium(III) Solvates-a Combined Spectroscopic and Theoretical Study. Inorganic Chemistry 2021, 60 (10), 7453-7464.
6. Kofod, N.; Nielsen, L. G.; Sørensen, T. J., Temperature Dependence of Fundamental Photophysical Properties of $\left[\mathrm{Eu}\left(\mathrm{MeOH}-\mathrm{d}_{4}\right)_{9}\right]^{3+}$ Solvates and [Eu.DOTA(MeOH-d $\left.\mathrm{d}_{4}\right]^{-}$Complexes. The Journal of Physical Chemistry A 2021, 125 (38), 8347-8357.

7. Marcus, Y.; Hefter, G., Ion pairing. Chem Rev 2006, 106 (11), 4585-4621.

8. Helm, L.; Merbach, A. E., Inorganic and bioinorganic solvent exchange mechanisms. Chem Rev 2005, 105 (6), 1923-59.

9. Wheelwright, E.; Spedding, F.; Schwarzenbach, G., The stability of the rare earth complexes with ethylenediaminetetraacetic acid. J Journal of the American Chemical Society 1953, 75 (17), 4196-4201.

10. Wood, S. A., The aqueous geochemistry of the rare-earth elements: Critical stability constants for complexes with simple carboxylic acids at $25^{\circ} \mathrm{C}$ and 1 bar and their application to nuclear waste management. Engineering Geology 1993, 34 (3), 229-259.

11. Betts, R. H.; Dahlinger, O. F., The heat and entropy of association of the complex ions formed by EDTA with the lanthanide elements in aqueous solition. 1959, 37 (1), 91100.

12. Gallagher, P. K., Absorption and Fluorescence of Europium(III) in Aqueous Solutions. 1964, 41 (10), 30613069.

13. Mackey, J.; Powell, J.; Spedding, F., A calorimetric study of the reaction of rare-earth ions with EDTA in aqueous solution. Journal of the American Chemical Society 1962, 84 (11), 2047-2050.

14. Bünzli, J. C. G.; Yersin, J. R., Fluorescence spectra and lifetime measurements of aqueous solutions of europium nitrate and perchlorate. Inorganic Chemistry 1979, 18 (3), 605-607.

15. Lis, S.; Choppin, G., Luminescence lifetimes of aqueous europium perchlorate, chloride and nitrate solutions. Materials chemistry \& physics 1992, 31 (1-2), 159-161.

16. Tanaka, F.; Yamashita, S., Luminescence lifetimes of aqueous europium chloride, nitrate, sulfate, and perchlorate solutions. Studies on the nature of the inner coordination sphere of europium (III) ion. Inorganic Chemistry 1984, 23 (14), 2044-2046.

17. Kimura, T.; Kato, Y., Luminescence study on the inner-sphere hydration number of lanthanide (III) ions in concentrated aqueous salt solutions in fluid and frozen states. Journal of alloys \& compounds 1998, 278 (1-2), 9297.

18. Breen, P. J.; Horrocks Jr, W. D., Europium (III) luminescence excitation spectroscopy. Inner-sphere complexation of europium (III) by chloride, thiocyanate, and nitrate ions. Inorganic Chemistry 1983, 22 (3), 536-540.

19. Silber, H. B., Europium(III) complexation reactions in water. Inorganica Chimica Acta 1987, 139 (1), 33-38.

20. Choppin, G. R., Structure and thermodynamics of lanthanide and actinide complexes in solution. Pure \& Applied Chemistry 1971, 27 (1-2), 23-42. 
21. Choppin, G.; Bertha, S., Lanthanide complexation: Inner versus outer sphere. Journal of Inorganic \& Nuclear Chemistry 1973, 35 (4), 1309-1312.

22. Choppin, G. R. Solution chemistry of the lanthanide elements; 1984.

23. Lundqvist, R., Hydrophilic complexes of the actinides. I. Carbonates of trivalent americium and europium. Acta Chem. Scand. A 1982, 36 (9).

24. Menon, M., Radiometric, potentiometric and conductometric measurements of the solubility and solubility product of europium trifluoride. Journal of Radioanalytical \& Nuclear Chemistry 1981, 63 (2), 283294.

25. Becker, P.; Bilal, B., Lanthanide-fluoride ion association in aqueous sodium chloride solutions at $25 \mathrm{C}$. Journal of solution chemistry 1985, 14 (6), 407-415.

26. Aziz, A.; Lyle, S., Partition of fluorocations of scandium, yttrium, lanthanum, americium (III) and cirium (III) between a cation-exchanger and an aqueous solution. Journal of Inorganic \& Nuclear Chemistry 1970, 32 (7), 2383-2387.

27. Vaněk, J.; Lubal, P.; Hermann, P.; Anzenbacher, P., Luminescent Sensor for Carbonate Ion Based on Lanthanide(III) Complexes of 1,4,7,10Tetraazacyclododecane-1,4,7-Triacetic Acid (DO3A). Journal of Fluorescence 2013, 23 (1), 57-69.

28. Vaněk, J.; Smrčka, F.; Lubal, P.; Třísková, I.; Trnková, L., Dual carbonate sensor based on Eu(III) complex of DO3A ligand. Monatshefte für Chemie Chemical Monthly 2016, 147 (5), 925-934.

29. Bridou, L.; Nielsen, L. G.; Sørensen, T. J., Using europium(III) complex of 1,4,7,10-tetraazacyclododecane1,4,7-triacedic acid Eu.DO3A as a luminescent sensor for bicarbonate. Journal of Rare Earths 2020, 38 (5), 498-505.

30. Abrahamer, I.; Marcus, Y. J. I. C., Interaction of lanthanide and nitrate ions in solutions. I. Inner-and outersphere coordination in aqueous solutions. 1967, 6 (11), 2103-2106.

31. Peppard, D.; Mason, G.; Hucher, I., Stability constants of certain lanthanide (III) and actinide (III) chloride and nitrate complexes. Journal of Inorganic \& Nuclear Chemistry 1962, 24 (7), 881-888.

32. Khopkar, P.; Narayanankutty, P., Effect of ionic media on the stability constants of chloride, nitrate and thiocyanate complexes of americium (III) and europium (III). Journal of inorganic \& nuclear chemistry 1971, 33 (2), 495-502.

33. Bansal, B.; Patil, S.; Sharma, H., Chloride, nitrate and sulphate complexes of europium (III) and americium (III). Journal of Inorganic \& Nuclear Chemistry 1964, 26 (6), 993-1000.

34. Andersson, S.; Eberhardt, K.; Ekberg, C.; Liljenzin, J.-O.; Nilsson, M.; Skarnemark, G., Determination of stability constants of lanthanide nitrate complex formation using a solvent extraction technique \% J Radiochimica Acta. 2006, 94 (8), 469-474.
35. Choppin, G. R.; Strazik, W. F., Complexes of trivalent lanthanide and actinide ions. I. Outer-sphere ion pairs. Inorganic Chemistry 1965, 4 (9), 1250-1254.

36. Piriou, B.; Svoronos, D.-R., Spectroscopic study of the $\mathrm{Eu}^{3+}$ ion in nitric acid aqueous solutions. Journal of the Less Common Metals 1985, 112 (1-2), 275-285.

37. Silber, H. B.; Gaizer, F.; Pham, T.; Strozier, M., Complexation differences between lanthanide nitrates from spectroscopic measurements in water. Journal of the Less Common Metals 1986, 126, 315-321.

38. Abrahamer, I.; Marcus, Y., The interaction of lanthanide and nitrate ions in solution-II: The relative interaction strength with water and nitrate in organic solvents. Journal of Inorganic \& Nuclear Chemistry 1968, 30 (6), 1563-1575.

39. Grygiel, W.; Starzak, M., Kinetics and symmetry studies of the inner hydration sphere of Eu3+ ion using environment-sensitive laser excitation spectroscopy. Journal of Luminescence 1997, 71 (1), 21-26.

40. Marcantonatos, M.; Deschaux, M.; Vuilleumier, J., Interactions of $\mathrm{Eu}^{3+}$ (aq) ${ }^{7} \mathrm{~F},{ }^{5} \mathrm{D}_{1}$ and ${ }^{5} \mathrm{D}_{0}$ levels with nitrate and inner-sphere $\left(\mathrm{EuNO}_{3}{ }^{2+}\right) *$ exciplex formation. Chemical Physics Letters 1981, 82 (1), 36-43.

41. Yaita, T.; Narita, H.; Suzuki, S.; Tachimori, S.; Motohashi, H.; Shiwaku, H., Structural study of lanthanides (III) in aqueous nitrate and chloride solutions by EXAFS. Journal of radioanalytical \& nuclear chemistry 1999, 239 (2), 371-375.

42. Sekine, T., Complex formation of La (III), Eu (III), $\mathrm{Lu}$ (III) and Am (III) with oxalate, sulphate, chloride and thiocyanate ions. Journal of Inorganic \& Nuclear Chemistry 1964, 26 (8), 1463-1465.

43. Irving, H.; Khopkar, P., The stability of the chloride complexes of europium. Journal of Inorganic \& Nuclear Chemistry 1964, 26 (9), 1561-1569.

44. Goto, T.; Smutz, M., Stability constants of lighter lanthanide(III) chloride complexes by a potentiometric method. Journal of Inorganic and Nuclear Chemistry 1965, 27 (3), 663-671.

45. Wheelwright, E.; Spedding, F.; Schwarzenbach, G., The stability of the rare earth complexes with ethylenediaminetetraacetic acid. Journal of the American Chemical Society 1953, 75 (17), 4196-4201.

46. Betts, R. H.; Dahlinger, O. F., THE HEAT AND ENTROPY OF ASSOCIATION OF THE COMPLEX IONS FORMED BY EDTA WITH THE LANTHANIDE ELEMENTS IN AQUEOUS SOLUTION. 1959, 37 (1), 91100.

47. Gallagher, P. K., Absorption and Fluorescence of Europium(III) in Aqueous Solutions. Journal of Chemical Physics 1964, 41 (10), 3061-3069.

48. Manning, P.; Monk, C., Solvent extraction studies of ion association. Some europium complexes. Transactions of the Faraday Society 1962, 58, 938-941.

49. Bukietyńska, K.; Mondry, A., f-f Transition intensities of europium (III) acetate complexes in a single crystal and in solution. Journal of alloys \& compounds 2001, $323,150-154$. 
50.

Kropp, J. L.; Windsor, M. W., Luminescence and energy transfer in solutions of rare earth complexes. II. Studies of the solvation shell in europium (III) and terbium (III) as a function of acetate concentration. The Journal of Physical Chemistry 1967, 71 (3), 477-482.

51. Silber, H. B., Europium (III) complexation reactions in water. Inorganica Chimica Acta 1987, 139 (12), 33-38.

52. Abrahamer, I.; Marcus, Y., Interaction of lanthanide and nitrate ions in solutions. I. Inner-and outersphere coordination in aqueous solutions. Inorganic Chemistry 1967, 6 (11), 2103-2106.

53. Andersson, S.; Eberhardt, K.; Ekberg, C.; Liljenzin, J.-O.; Nilsson, M.; Skarnemark, G., Determination of stability constants of lanthanide nitrate complex formation using a solvent extraction technique. Radiochimica Acta 2006, 94 (8), 469-474.

54. Hale, C. F.; Spedding, F. H., Thermodynamics of the association of aqueous europium(III) and sulfate ions. The Journal of Physical Chemistry 1972, 76 (13), 18871894.

55. Barnes, J. C., 739. Stability constants and spectra of some lanthanide complexes. Journal of the Chemical Society (Resumed) 1964, (0), 3880-3885.

56. Purdie, N.; Vincent, C. A., Ultrasonic absorption in the lanthanide sulphates. Transactions of the Faraday Society 1967, 63, 2745-2757.

57. Laurie, S. H.; Monk, C. B., 620. Dissociation constants of some barium, europium, and hexaamminecobalt ion-pairs by use of sparingly soluble iodates containing radiotracers. Journal of the Chemical Society (Resumed) 1963, (0), 3343-3347.

58. De Carvalho, R.; Choppin, G., Lanthanide and actinide sulfate complexes-I: Determination of stability constants. Journal of Inorganic \& Nuclear Chemistry 1967, 29 (3), 725-735.

59. Goto, T.; Smutz, M., Stability constants of lighter lanthanide (III) chloride complexes by a potentiometric method. Journal of Inorganic \& Nuclear Chemistry 1965, 27 (3), 663-671.

60. Shannon, R. D., Revised effective ionic radii and systematic studies of interatomic distances in halides and chalcogenides. Acta crystallographica section A 1976, 32 (5), 751-767.

61. Choppin, G.; Unrein, P., Halide complexes of the lanthanide elements. Journal of Inorganic \& Nuclear Chemistry 1963, 25 (4), 387-393.

62. Degischer, G.; Choppin, G. R., Malonate complexing of lanthanide ions. Journal of Inorganic \& Nuclear Chemistry 1972, 34 (9), 2823-2830.

63. Nawrocki, P. R.; Kofod, N.; Juelsholt, M.; Jensen, K. M. Ø.; Sørensen, T. J., The effect of weighted averages when determining the speciation and structure-property relationships of europium(iii) dipicolinate complexes. Physical Chemistry Chemical Physics 2020, 22 (22), 1279412805.

64. Thomsen, M. S.; Anker, A. S.; Kacenaukaite, L.; Sørensen, T. J., We are Never Ever Getting (back to) Ideal
Symmetry: Structure and Luminescence in a TenCoordinated Europium(III) Sulfate Crystal. In preparation 2022.

65. Beeby, A.; M. Clarkson, I.; S. Dickins, R.; Faulkner, S.; Parker, D.; Royle, L.; S. de Sousa, A.; A. Gareth Williams, J.; Woods, M., Non-radiative deactivation of the excited states of europium, terbium and ytterbium complexes by proximate energy-matched $\mathrm{OH}, \mathrm{NH}$ and $\mathrm{CH}$ oscillators: an improved luminescence method for establishing solution hydration states. Journal of the Chemical Society, Perkin Transactions 2 1999, (3), 493504. 